\title{
因动漫作品中的 “暴力” 内容而引发的思考
}

范亚楠

大连工业大学艺术设计学院

DOI:10.32629/er.v3i3.2576

[摘 要] 随着 “喜羊羊暴力” 案的出现, 相关的與论遍布网络和社会, 很大一部分人将矛头指向动漫制作公司和播放机构, 把动漫中的暴力内容 视为犯罪事件的源头。笔者认为大众对动漫中的暴力内容存在误解, 并对一些概念缺乏专业的认识。在下文中, 笔者将对动漫中暴力内容相关的 概念进行详细的解释和说明,并结合实际例子来论证自己的观点和看法。

[关键词] 暴力; 动漫中的暴力元素; 暴力动漫

在前几年, 国内的知名动漫作品《喜羊羊与灰太狼》被认为是内容暴 力失度, 语言粗俗, 一时间不仅仅制作公司受到社会谴责, 就连播出机构中 央电视台也被舆论扣上了只为收视率赚钱而对问题作品来者不拒, 照单全 收的帽子。有评论者在文章中称人们已经不同程度地受到了动漫中暴力内 容的影响, 为了孩子, 为了社会, 为了职业操守, 我们的动漫制作者应该坚 持正确的制作标准, 努力创作出格调高雅, 情感高尚, 另观众喜闻乐见的艺 术精品。针对这样的评论, 笔者认为发声者对动漫作品中的暴力内容有所 偏见, 并且对动漫本身也缺乏专业性的认识。

在《日本动漫影响力调查报告》一书中曾提到过, 暴力、动漫中的暴 力元素和暴力动漫作品这三个概念的意义是不同的。如果不能够将它们区 分看待, 那么只能是泛泛而谈。

首先是 “暴力” 这个词, 《现代汉语词典》中的解释是: (1) 武力, 强 制的力量; (2)特指国家的力量; 维基百科的解释是: “基于故意侵害或故 意伤害他人的心理, 而使用激烈且富有强制性力量之行为, 包括有形物理 或无形心理。具体可分为 “直接暴力’ 、结构性暴力’ 、文化暴力”。直 接暴力即直接造成肉体或心理伤害的作为, 其直接中断或限制人类的生 存、幸福, 认同和自由。结构性暴力是由于政治, 经济, 社会体制所形成权 利与资源分配的不平等而产生的隐性暴力。文化暴力也被理解为文化霸权, 是依靠对文化, 教育, 以及媒体上的控制, 以规范是非对错。”从上解释中 可以看出, 在现实中, “暴力” 是带有贬义与负面的, 在法律上是不予以鼓 励的。

其次是 “动漫中的暴力元素”, 是指动漫作品中所呈现的打斗、杀戮、 血腥、武器、强暴、伤害这样的暴力行为和画面, 这些暴力元素在作品中 只是作为一种叙事道具或者叙事策略, 而并不等于或者代表作品的主题思 想。尤其是在以动作作为叙事核心的动漫作品中, 由于其特定的表现内容 决定了 “暴力” 存在的必然性。例如国内早期引进的日本动漫作品《圣斗 士星矢》中的 “天马流星拳”, “庐山升龙霸” 等等。

最后是 “暴力动漫” 作品, 参考汪献平著的《暴力电影一一表达与意 义》一书中对 “暴力电影” 的定义, 可以理解为, 即并非所有存在着暴力元 素的动漫作品都是暴力动漫, 有些存在大量打斗场面的动漫只能算是热血 动漫, 暴力动漫是以主人公的暴力行为直接推动故事情节的发展, 这种暴 力行为与作品主题思想密切相连, 重在体现暴力思想而非简单直接的暴力
行为。《死亡笔记》就是典型的暴力动漫作品, 从头到尾以智斗为主, 但内 容有推崇独裁性质 “正义” 的嫌疑, 进一步说是有着暴力崇拜的嫌疑。

“暴力动漫” 作品虽然与现实中的 “暴力” 不是对等的, 但是也不像 暴力元素那样仅仅作为一种叙事手法出现在作品当中。这样的作品, 内容 复杂富有逻辑性, 发人深思, 适合有控制力和判断力的成年人观看, 但不适 合未成年人, 尤其是一些判断力不强, 思维不完善的中小学生, 很容易受到 作品中一些负面内容的误导或影响。笔者认为, 由于当下国内还未对动漫 影视作品实行分级制度, 所以未成年人在观看动漫作品时需要经过家长的 同意, 或是在家人的陪同下观看。

文章开头提到的两部作品只算是含有暴力元素的作品, 而非 “暴力动 漫”。暴力元素是在动漫作品中普遍存在的, 如果说作品内容一旦涉及了暴 力元素便要遭到禁播和封杀的话, 那恐怕几乎就没什么作品可以观看了, 就算是《机器猫》这样的作品, 也会出现暴力元素, 例如胖虎和小夫经常欺 负大雄, 抢夺他的物品, 做错事每次还理直气壮。这样的内容就像现实中的 校园霸凌一样。如果说 “喜羊羊暴力” 案逻辑是合理的话, 即认为小孩子 在现实中作出暴力事件都是受动画片中暴力元素的影响, 然后把一部分责 任推卸给动漫制作公司和播放机构, 那么现实中的校园霸凌事件的犯罪者 也可以说是在模仿胖虎和小夫, 然后间接把责任推卸给《机器猫》的制作 公司。如此看来这逻辑明显是不合理的, 因为不止是日本动漫, 国产的《葫 芦兄弟》, 欧美的《猫和老鼠》中都会出现打的头破血流的场面, 如果是按 开头评论中的标准, 这些作品都不应该被搬上苂幕。但相反, 这些动漫都是 国内少年儿童最为喜爱的经典作品。

所以说, 在看待动漫中的暴力内容时, 绝不能想当然地把一些概念混 为一谈。现如今暴力元素已广泛地存在于动漫文本之中, 如果说还只是从 社会学和心理学角度, 关注对未成年人的身心健康影响来说明问题, 而忽 视了对动漫作品本身的基本解读, 那么显然是不具有说服力的。

[参考文献]

$[1]$ 陈奇佳, 宋晖.《日本动漫影响力调查报告》一一当代中国大学生文 化消费偏好研究 $[M]$. 人民出版社,2009.

[2]汪献平.暴力电影——表达与意义[M].中国传媒大学出版社,2008. [3]陈奇佳.日本动漫艺术概论[M].上海交通大学出版社,2006. 